\title{
Effects of hypericin on the oxidative stress and modulation of cytochrome P450 (CYP1A) activity in microsomes
}

https://doi.org/10.33263/BTEB214.024027

\author{
Renata Kubínová ${ }^{1}$, Václav Suchý ${ }^{1}$, Marie Valentová ${ }^{1, *}$
}

1 Department of natural Drugs, Faculty of Pharmacy, University of Veterinary and Pharmaceutical Sciences, Palackého 1/3, 612 42 Brno, Czech Republic

*corresponding author e-mail address: valentovam@vfu.cz

\section{ABSTRACT}

Hypericin is a pigment present in the widely distributed medicinal plant Hypericum perforatum L. (Hypericaceae). In our research, hypericin was found to be an inhibitor of $\mathrm{NADPH} / \mathrm{Fe}^{2+}$ induced microsomal lipid peroxidation and NADPH-dependent lucigenin chemiluminescence emission in vitro. Hypericin also inhibited the microsomal CYP1Adependent 7-ethoxyresorufin $O$-deethylase (EROD) which participates in the metabolic activation of xenobiotics including chemical carcinogens.

Keywords: chemiluminescence; EROD activity; Hypericumperforatum; lipid peroxidation

\section{INTRODUCTION}

Hypericum perforatum (Hypericaceae), a perennial flowering plant, is distributed in Europe, Asia, North Africa and North America. This plant is well known in traditional medicine in Europe as well as in Traditional Chinese Medicine. It is effective especially in the treatment of mild to moderate depression (Mennini et al., 2004). The drug acts as a sedative and has been known to contain a red dianthrone pigment hypericin, which has been assumed to be a primary active constituent with significant receptor affinity for GABA and benzodiazepine receptors (Cott, 1997). Hypericin is a natural photosensitizer, which possesses white light-induced antitumour activity in vivo (Vandenbogaerde et al., 1996).

Under optimal conditions of exposure to light, hypericin exhibited a strong inhibitory activity against HSV-1 (herpes simplex virus) and HIV-1 (human immunodeficiency virus). There was a significant reduction of a light-induced antiviral activity of hypericin under hypoxic conditions. Only when the concentration of hypericin reached the cytotoxic level there was an apparent lightindependent antiviral effect (Hudsonet al.,1994; Parket al.,1998).

$H$. perforatum is one of the most commonly used herbal medications, nevertheless clinical reports indicate that $H$. perforatum increases the activity of cytochrome P450 enzyme and can reduce plasma concentrations of certain drugs. In search for compounds with chemoprotective activity we isolated hypericin from $H$. perforatum and evaluated its antioxidant and CYP1A modulating activities.

\section{MATERIALS AND METHODS}

\section{General}

Hypericum perforatum L. was collected in Medicinal Herbs Centre of Masaryk University Brno and identified by prof. Václav Suchý, Department of Natural Drugs, VFU Brno, Czech Republic. Hypericin was isolated and purified from the aerial 
parts of $H$. perforatum and identified by spectral methods. Spectral data corresponded with data published previously (Piperopoulos et al., 1997). All the chemicals were purchased from Sigma Chem. Co. (Czech Republic).

\section{Isolation of Microsomal Fraction}

The hepatic microsomal fraction was isolated from $\mathrm{C} 57 \mathrm{BI} / 6$ mouse liver tissue by homogenization and differential centrifugation. The microsomes were washed once, resuspended in $0.05 \mathrm{M}$ Tris- $\mathrm{HCl}$ buffer, $\mathrm{pH} 7.5$, containing $20 \%$ of glycerol and $0.1 \mathrm{mM}$ EDTA and stored at $-80{ }^{\circ} \mathrm{C}$ until used.

\section{Determination of antioxidant activity}

The inhibition of $\mathrm{Fe}^{2+} / \mathrm{NADPH}$-dependent lipid peroxidation was determined in vitro by the method of thiobarbituric acid reactive species (TBARs) (Uchiyama et al., 1978). The reaction mixture contained microsomes, $0.1 \mathrm{M}$ Tris- $\mathrm{HCl}$ buffer, $\mathrm{pH}$ 7.6, $10 \mu \mathrm{L}$ hypericin dissolved in DMSO or DMSO alone as the control and an oxygen radicals generating system. The concentration of TBARs was measured at $532 \mathrm{~nm}$. Lucigenin (1.7 $\mathrm{mM}$ ) was used as a chemiluminescence amplifier and NADPH $(0.3 \mathrm{mM})$ as a generating system in the $C L$ method (Scholz et al., 1990). The reaction mixture contained microsomes, $10 \mu \mathrm{L}$ hypericin dissolved in DMSO or DMSO alone as the control.

\section{Determination of cytochrome}

P4501A

\section{(CYP1A)-dependent EROD activity}

The microsomal 7-ethoxyresorufin O-deethylase (EROD) was determined using direct fluorimetric method (Prough et al., 1997). The reaction mixture contained microsomes, $2 \mu \mathrm{M}$ ethoxyresorufin, $0.1 \mathrm{M}$ Tris- $\mathrm{HCl}$ buffer, $\mathrm{pH} 7.6$ and $0.3 \mathrm{mM} N A D P H$. The in vitro inhibition of the EROD activity was assayed in the same reaction mixture with addition of $10 \mu \mathrm{L}$ hypericin dissolved in DMSO or DMSO alone as the control.

\section{RESULTS AND DISCUSSIONS}

We evaluated the effect of hypericin on $\mathrm{Fe}^{2+} / \mathrm{NADPH}$-enhanced microsomal lipid peroxidation and on lucigenin-amplified chemiluminescence $(C L)$ induced by NADPH in vitro. The effect of hypericin on cytochrome P4501A (CYP1A) activity, which is involved in a bioactivation of xenobiotics, was tested in a microsomal fraction of $\mathrm{C} 57 \mathrm{Bl} / 6$ mouse liver. Natural antioxidant quercetin was used as a standard in the experiments.

The microsomal lipid peroxidation was induced enzymatically by NADPH and $\mathrm{Fe}^{2+}$. Hypericin inhibited production of thiobarbituric acid-reacting substances (TBARs) in a concentration-dependent manner but was weaker compared to the standard in the concentration $10 \mu \mathrm{M}$ (figure 1). The $\mathrm{IC}_{50}$ values were $5 \mu \mathrm{M}$ for hypericin and $4.5 \mu \mathrm{M}$ for quercetin. In the previous study, hypericin was found to have no cytotoxic effect in the dark while significantly stimulated lipid peroxidation after irradiation with visible light (Hadjur et al., 1996).

As shown in figure 2, hypericin inhibited lucigenin-augmented chemiluminescence (CL) induced by reactive oxygen species (ROS), mainly by superoxide. $\mathrm{IC}_{50}$ for hypericin and quercetin were $1 \mu \mathrm{M}$ and $194 \mu \mathrm{M}$, respectively.

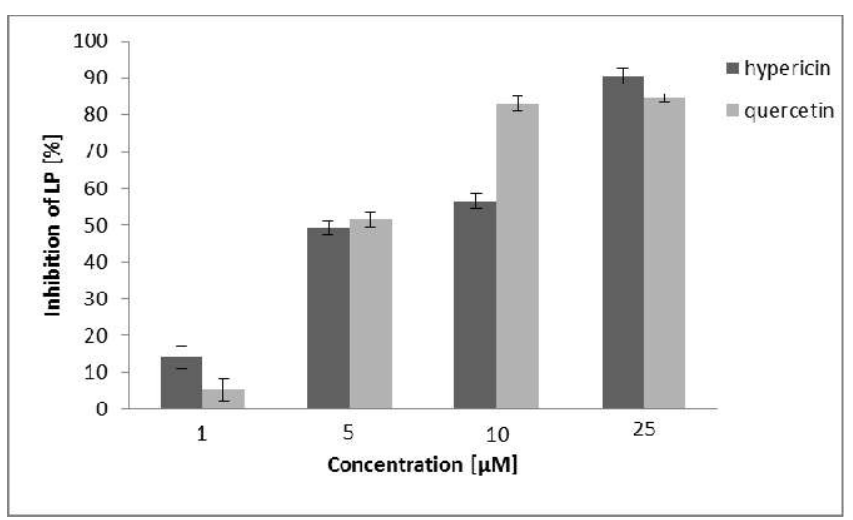

Figure 1. In vitro inhibition of the $\mathrm{Fe}^{2+} / \mathrm{NADPH}$-dependent lipid peroxidation.LP, lipid peroxidation in hepatic microsomes. Values are expressed as mean $\pm S E M, n=6$.

$\mathrm{CL}$ emission was measured upon incubation with NADPH. As it was reported, photoactivated hypericin produces singlet oxygen and superoxide anion radical via the inhibition of mitochondrial succinoxidase and oxidative stress-initiated mitochondrial damage as a key target in hypericin phototoxicity (Johnson et al., 1998). On the other hand, hypericin caused inhibition of superoxide 
Biomaterials and Tissue Engineering Bulletin

generation of neutrophil via a mechanism involving the inhibition of tyrosin kinase, protein kinase $\mathrm{C}$ and NADPH oxidase. $\mathrm{IC}_{50}$ for NADPH oxidase was $10 \mathrm{nM}$ (Nishiuchi et al., 1995). In the inhibition mechanism of lipid peroxidation and $\mathrm{NADPH}$-induced lucigenin $\mathrm{CL}$ either scavenging reactive oxygen species (ROS) or inhibition of NADPH oxidase dependent enzymatic reactions generated by ROS can be involved.

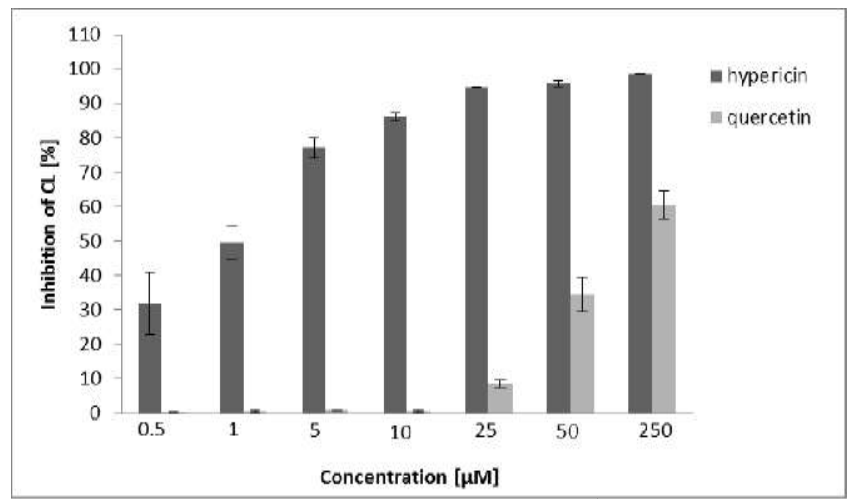

Figure 2. In vitro inhibition of lucigenin-amplified chemiluminescence. $\mathrm{CL}$, chemiluminescence in hepatic microsomes. Values are expressed as mean \pm SEM, $n=6$.

The potency of hypericin to inhibit the CYP1A-dependent 7-ethoxyresorufin O-deethylase activity (EROD) in vitro is given in the figure 3 .
Hypericin inhibited the EROD production in a concentration dependent manner in the range 5$25 \mu \mathrm{M}$ and the potency of hypericin was lower than thst of quercetin. The $\mathrm{IC}_{50}$ values were $2 \mu \mathrm{M}$ for quercetin and $13 \mu \mathrm{M}$ for hypericin. The EROD activity was measured by the fluorescence method. The inhibition potency of hypericin can be caused by its phototoxicity because the reaction mixture was under irradiation. In human hepatocyte model hypericin had no effect on CYP enzymes but hyperforin treatment resulted in a significant increase of activity of CYP3A4 and CYP2C9 (Komoroski et al.,2004).

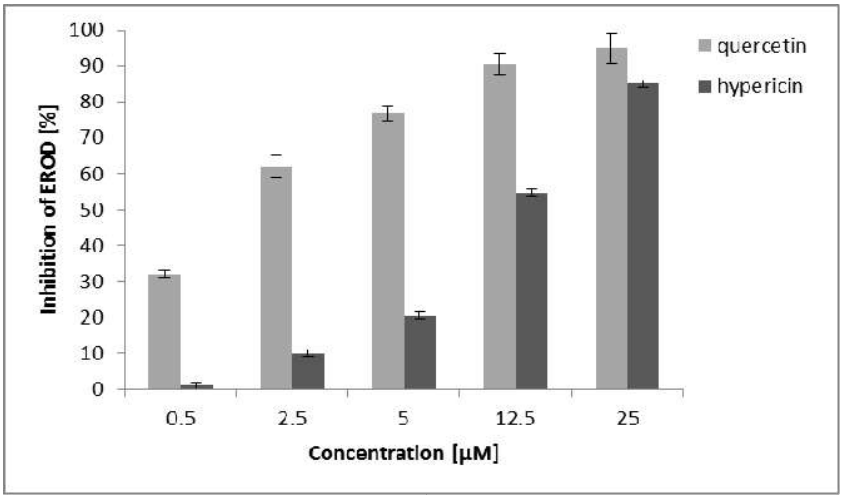

Figure 3. In vitro inhibition of the CYP1A-dependent EROD activity. EROD, 7-ethoxyresorufin O-deethylase activity in hepatic microsomes. Values are expressed as mean \pm SEM, $n=3$.

\section{CONCLUSIONS}

In conlusion, hypericin represents a promising natural compound with interesting biological activities. However, its phototoxicity is a limiting factor for its use as a pharmacotherapeutic agent.

\section{REFERENCES}

Cott, J.M.(1997).In vitro receptor binding and enzyme inhibition by Hypericumperforatum extract. Pharmacopsychiatry: 30, 108-112.

Johnson, S.A., Dalton, A.E. and Pardini, R.S.(1998).Timecourse of hypericinphototoxicity and effect on mitochondrial energies in EMT6 mouse mammary carcinoma cells.Free Radical Biology and Medicine: 25, 144-152.

Hadjur, C., Richard, M.J., Parat, M.O., Jordon, P. and Favier, A.(1996).Photodynamic effects of hypericin on lipid peroxidation and antioxidant status in melanoma cells.Photochemistry and Photobiology: 64, 375-381.
Hudson, J.B., Harris, L., Towers, G.H.(1993).The importance of light in the anti-HIV effect of hypericin. Antiviral Research: 20, 173-178.

Komoroski, B.J., Zhang, S., Cai, H., Hutzler, J.M., Frye, R., Tracy, T.S., Strom, S.C., Lehmann, T., Ang, C.Y., Cui, Y.Y. and Venkataramanan, R.(2004).Induction and inhibition of cytochromes p450 by the st. John's wort constituent hyperforin in human hepatocyte cultures. Drug Metabolism and Disposition: 32, 512-513.

Mennini, T. and Gobbi, M.(2004).The antidepressant mechanism of Hypericumperforatum. Life Sciences: 75, 1021-1027.

Nishiuchi, T., Utsumi, T., Kanno, T., Takehara, Y., Kobuchi, H., Yoshioka, T., Horton, A.A., Yasuda, T. and Utsumi, 
Biomaterials and Tissue Engineering Bulletin

K.(1995).Inhibition of neutrophil superoxide generation by hypericin, an antiretroviral agent. Archives of Biochemistry and Biophysics: 323: 335342.

Park, J., English, D.S., Wannemuehler, Y., Carpenter, S. and Petrich, J.W.(1998).The role of oxygen in the antiviral activity of hypericin and hypocrellin. Photochemistry and Photobiology: 68, 593-597.

Piperopoulos, G., Lotz, R., Wixforth, A., Schmierer, T. and Zeller, K.P.(1997).Determination of naphthodianthrones in plant extracts from Hypericumperforatum L. by liquid chromatographyelectrospray mass spectrometry. Journal of Chromatography B: Biomedical Sciences and Applications: 695, 309-316.
Prough, R.A., Burke, M.D. and Mayer, R.T. (1978). Direct fluorometric methods for measuring mixed function oxidase activity. Methods in Enzymology: 52c, 372377.

Scholz, W., Schütze,K., Kunz, W.and Schwarz, M.(1990).Phenobarbital enhances the formation of reactive oxygen in neoplastic rat liver nodules. Cancer Research: 50, 7015-7022.

Uchiyama, M. and Mihara, M. (1978). Determination of Malondialdehyd Precursor in Tissues by Thiobarbituric Acid Test. AnalyticalBiochememistry: 20, 271-278.

Vandenbogaerde, A.L., Geboes, K.R., Cuveele, J.F., Agostinis, P.M., Merlevede, W.J. and DeWitte, P.A.(1996).Antitumour activity of photosensitized hypericin on A431 cell xenografts. Anticancer Research: 16, 1619-1625.

\section{ACKNOWLEDGEMENTS}

This work was supported by the grant from the Czech Ministry of Education FRVS 0997.

\section{Conflicts of Interest}

The authors declare no conflict of interest.

(C) 2015 by the authors; licensee AMG Transcend, Bucharest, Romania. This article is an open access article distributed under the terms and conditions of the Creative Commons Attribution license (http://creativecommons.org/licenses/by/4.0/). 